\title{
Communicating research in mathematics education: theoretical and ethical problems
}

\author{
Candia Morgan \\ University College London Institute of Education
}

\begin{abstract}
Connections between research, policy and practice are often problematic as politicians and practitioners bemoan the irrelevance of research; while researchers complain that their work is misunderstood. In this chapter, the movement of research from the field of research into other fields is understood through the lens of Bernstein's notion of recontextualisation. Examples are given from a recent project investigating changes in mathematics examinations in England, illustrating how research results may be incorporated into alternative discourses to support pre-existing positions and values. This raises questions for ethical researchers.
\end{abstract}

\section{Introduction}

Educational research is often criticised for failing to provide results that can be used to inform practice, and educational researchers are criticised for failing to communicate with practitioners and policy makers. Measures of the "impact" of research outside the academic domain now play an important role in the evaluation and funding of research in the UK, and elsewhere in the world. Apart from the need to meet the expectations of our employers, partaking in the ritual of research identified by Lundin and Christensen (in this volume), there are strong ethical and political arguments to be made for educational researchers to pay serious attention to how their work relates to the experiences and practices of students and teachers. However, my concern in this chapter is not so much with whether research is communicated "effectively" and can inform "evidence-based practice" (Slavin, 2002) as with the nature of the communication, with the ways in which research outcomes are transformed as they move from the field of research into the fields of policy and practice and with the possible consequences of such transformation.

This concern is motivated by my own recent experience, observing the ways in which researchers, teachers and other practitioners have responded to my attempts to communicate research outcomes and reflecting on how various groups may interpret these outcomes. As I wrote the previous sentence, I hesitated over the word interpret, wondering whether I wanted to write misinterpret. This hesitation is at 
the centre of the problem I address in this chapter. The outcomes of my research and my own interpretation of these outcomes are the product of my intellectual work and that of my co-workers ${ }^{1}$. In fact, every stage of the research process was shaped by our theoretical assumptions and decisions based on these assumptions, whether these were consciously acknowledged and openly stated or not: the choice of research focus; statement of research questions; choices of data, methods of data collection and analysis; identification and description of outcomes; choices about which outcomes to report; decisions about how to report and to whom. Can I therefore claim ownership of the outcomes and the right to say that my interpretation is the only correct interpretation? However strongly I may feel that I "own" the research and that my interpretation is correct, there are two reasons why the answer to this question has to be no.

The first reason is rooted in my understanding of the nature of communication, semiosis and discourse. Meaning does not reside in words, images or physical objects. It is produced in social practice - in the ways that words, images and objects are brought into being and used by people in order to perform functions within a specific practice. As outcomes of research are disseminated (by whatever means of communication) beyond the particular practice within which they were produced, the kinds of functions they may perform change. Moreover, as they are used, they come into relation with the range of semiotic resources already in use within the new practice, enabling the production of new kinds of uses - new meanings. The interpretation of research outcomes is thus always relative to the practice within which they are functioning. In order to think about this interpretation, I make use of Bernstein's notion of recontextualisation, as developed by Morgan, Tsatsaroni and Lerman (2002), to analyse and understand how the outcomes and discourse of educational research are transformed as they move from the field of research into the field of policy and the field of practice. Bernstein (2000) contends that, as a discourse (in this case the discourse of educational research) moves from one site to another, a space is created "in which ideology can play" (p.32). This play of ideology transforms the original discourse into a new discourse. The process of transformation involves selective appropriation from the original discourse, refocusing that which is appropriated and relating it to elements drawn from other discourses. The way in which this occurs is ideological in that it varies according to the interests of the agents in the recontextualising field. We must therefore expect that when the outcomes of research are disseminated into the fields of policy and practice they will be transformed. A challenge for researchers, which I return to later in this chapter, is to anticipate the nature of this transformation and to 'manage' it so that the uses made of the research as it moves into new fields are as consistent as possible with the ethical and political principles of the researchers, including ethical consideration of the relationships among

\footnotetext{
${ }^{1}$ The research discussed in this paper was undertaken together with Anna Sfard and Sarah Tang. The views expressed here, however, are entirely my own responsibility.
} 
the various research participants and other interested groups as discussed by Wagner (in this volume).

The second reason why I cannot claim a right of ownership of 'my' research is an economic reason. I referred above to research outcomes as the product of intellectual work. As an employee of a university in the UK, I sell my labour to my employer and, indirectly, to the UK state, which funds much of the research activity of the university. Of course, direct analogies between material and intellectual labour are problematic. As researchers, we may not experience alienation from the products of our labour in the same way as the factory worker, who sees her product taken from her and sold for the profit of the capitalist. In Marxist economic terms we are "unproductive" workers in that we do not directly produce surplus value (Draper, 1978, p.490). Nevertheless, it would be naïve to imagine that our employers and the state have no interest in the research we produce and in the uses to which it is put. A direct interest of the university employers is in the exchange of 'quality' and 'impact' for further research funding and recruitment of students. More indirectly, the state has an interest in research findings in so far as these serve to support their exercise of government.

Of course, not all the products of intellectual labour directly support the state and its governance. Indeed, the work of researchers represented in this volume and of many others concerned with socio-political aspects of education is often deeply critical of systems and policies of government. However, in a state in which researchers have so-called academic freedom, the state's interest in research outcomes is served not by direct suppression of opposition but by two other strategies: dismissing it by construing it as irrelevant or inadequate; or recruiting it through a process of recontextualisation. ${ }^{2}$ The first of these strategies may be seen, for example, in the valorisation of randomised controlled trials (RCTs) as a means of providing evidence of "what works". For example, the UK Secretary of State for Education stated:

We need more hard evidence in the education debate. [...] Randomised controlled trials offer us the opportunity to establish which policies genuinely help children. I am delighted the DfE is embracing a more rigorous approach towards evidence. (Michael Gove, 2013) ${ }^{3}$

Forms of research that address aspects of education that are not susceptible to the kinds of measurement required by RCTs or that result in more contextualised and nuanced outcomes are construed in this statement as lacking rigour, providing inadequate "soft" evidence, not "genuinely" helping children. This valorisation of RCTs has even been materialised in some cases by restriction of funding for other

${ }^{2}$ Of course, in societies with separation of state, academic and commercial interests, critical research may well gain a voice through publication. This creates opportunities for development of alternative discourses drawing on such research in ways that may compete with official discourses.

${ }^{3}$ https:/www.gov.uk/government/news/new-randomised-controlled-trials-willdrive-forward-evidence-based-research, accessed 11 May 2015 
forms of research. For example, a major educational foundation in the UK commissions large-scale research investigating the effectiveness of educational innovations, with the condition that the research should involve RCT.

The second strategy, the recruitment of research to the interests of the state, is the main focus of this chapter. I will explore issues related to the recontextualisation of educational research through discussing examples taken from a recent research project. "The Evolution of the Discourse of School Mathematics" (EDSM) addressed the question of how expectations about student participation in mathematical activity have changed over time in England. In this project we used high stakes examinations from the end of compulsory schooling - the General Certificate of Secondary Education (GCSE), taken by almost all students at age 16 - as our lens onto the expectations of the curriculum, taking a discourse analytical approach to interrogate the nature of the mathematical activity expected of students. From the beginning we were conscious of a political dimension to this research. In England, as in many countries, the curriculum and examinations are regulated by the state and performance in assessments in mathematics are used as one of the key measures of the success (or failure) of the education system. In particular, we were aware that change in examinations over time is likely to be construed by many audiences in terms of a discourse about 'standards' - a discourse that is found in policy debates and in public media (Sfard, 2009), which is used as a means of justifying changes to curriculum, assessment and teachers' working conditions.

In the proposal to the UK government funded Economic and Social Research Council we attempted to distance ourselves from this discourse, writing:

We argue that the analysis of change produced by this approach will provide insight into how changes in curriculum and assessment may affect students' mathematical learning. We do not seek to address the complex question of comparability of standards over time, but to consider at a detailed level the ways in which students' mathematical learning may have changed.

The aim of the research was thus to produce a description. The description in itself may seek (or claim) to be free of value judgements, but of course descriptions may be used in a variety of ways and users (including the researchers themselves) ascribe their own values to the terms of the description. Indeed, it could be argued that the notion of value-free description is impossible, given that the writing and reading of any descriptive text necessarily take place within some social practice that ascribes its own values to the objects, processes and qualities present in the text. In the case of the EDSM project, the values of the researchers were not explicitly stated in the original proposal but may be seen to include implicit valuing of coherence of curriculum and assessment with some unarticulated notion of "quality" of mathematics and student mathematical experience. Vagueness in the presentation of researcher values may be seen as a gambit to enhance the possibil-

${ }^{4}$ Funded by the UK Economic and Social Research Council, grant reference: RES-062-23-2880. 
ity of gaining funding to undertake the research; at the same time it opens up greater opportunities for readers to interpolate their own values.

The ascription of unintended values to research outcomes is not a new problem and is not confined to the transformation of research descriptions as they move into fields outside the university. Paul Dowling, speaking to a group of research students, deliberately misquoted Marx; my recollection of his words goes something like: "sociological research does not try to change the world; the point is to describe it". ${ }^{5}$ Dowling's research aim has always been to create languages of description (Dowling, 2009), yet, when applied to the empirical field, the resulting descriptions are inevitably interpreted, and used by many if not most readers, including readers within the mathematics education research field, in value-laden ways. The imputation of values to descriptions introduces a strong potential to motivate action and consequent changes to the world. For example, his most widely known work in mathematics education produced descriptions of textbooks designed for higher and lower attaining pupils (Dowling, 1998). Part of his description focused on the identities and trajectories projected for students in the two types of texts. Using the descriptive terms "apprenticed" and "dependent", Dowling concludes that the strategies used in the books for higher attaining students projected middle class identities (envisaging future professional employment and other middle class occupations) and "apprenticed" students into mathematical practices, positioning them as potentially able to engage as independent subjects in mathematical practices. On the other hand, the books for lower attaining students projected working class identities (envisaging future manual employment) and construed their positioning with respect to mathematics as "dependent", lacking access to the regulative principles of mathematical activity. ${ }^{6}$ While for Dowling this language may function simply as description, in other discursive practices, including those common within mathematics education and mathematics education research, the terms "apprenticed" and "dependent" are value laden and are likely to be given connotations beyond those explicitly given by Dowling's definitions. The notion of access to higher levels of mathematics is also value laden: access is positively valued in contrast to restriction or denial; dependence contrasts with the valuing of independence as a goal of a liberal/progressive ${ }^{7}$ mode of pedagogy; while mathematics in general and higher mathematics in particular are generally unquestioned positive goods (though see Pais \& Valero, 2014). As users of Dowling's research interpolate such values, they transform the description into ar-

\footnotetext{
${ }^{5}$ Marx, Theses on Feuerbach: "Philosophers have hitherto only interpreted the world in various ways; the point is to change it"

${ }^{6}$ It is of course very possible that Paul Dowling would contest the account of his research that I am presenting here. I am using his research for a new purpose, relating it to my own theoretical perspective and making it serve the interests of the arguments presented in this chapter.

7 'Liberal/progressive' in the sense used by Bernstein (Bernstein, 2000) and Lerman and Tsatsaroni (Lerman \& Tsatsaroni, 1998)
} 
guments for change. For example, Heggarty and Pepin's (2002) study of textbooks in three countries draws on Dowling's work as evidence of the stereotyping of different social groups in schools in England, incorporating this into a wider critique of current practice and culminating in recommendations for change, suggesting that textbooks in England should "begin to embrace the richer view of mathematics and its learning which takes account of children as makers of knowledge and not as receivers of that knowledge" (p.588).

In the examples from the EDSM project that follow, I identify and discuss aspects of the description of mathematics examinations resulting from our research that have shown themselves to be susceptible to recontextualisation. In particular, I focus on how these lend themselves to recruitment by existing official policy discourses.

\section{Examples from the EDSM project}

The approach taken by the EDSM project focused on the discourse of mathematics examinations, using a range of discursive and linguistic analytical tools. Previous studies of the language of mathematics examinations have tended to treat the language in which questions are written as independent of the mathematical activity demanded of students. Researchers have thus identified the effects of linguistic factors and other communicational aspects (such as graphic elements and the layout of text) as "obscuring" the mathematics (e.g., Fisher-Hoch, Hughes, \& Bramley, 1997; Pollitt, Hughes, Ahmed, Fisher-Hoch, \& Bramley, 1998; Shorrocks-Taylor \& Hargreaves, 1999) - making examination questions more or less difficult for students. In the EDSM project, we have taken a different theoretical perspective on the relationship between language and mathematical activity. Drawing on Halliday's social semiotics (Halliday, 1978) and Sfard's communicational theory (Sfard, 2008), we conceptualise the language in which mathematics is communicated as constitutive of the mathematics itself. Different forms of communication in an examination question entail differences in the mathematical activity expected of a student. Our investigation of discursive differences between examinations set in different years is thus not concerned only with changes in levels of difficulty (although this is one aspect of the research) but is more centrally concerned with the nature of the mathematics with which students are expected to engage. See Morgan and Sfard (forthcoming) for an account of the theoretical and methodological framework of the project.

\section{Case 1 - Grammatical complexity}

One of the textual characteristics we investigated in the examination papers was grammatical complexity. In particular, as reported in Morgan, Tang and Sfard 
(2011), we looked at the extent of use of complex nominal groups, a characteristic component of scientific registers (Halliday, 1993), measuring their recursive depth $^{8}$. Comparing examination papers from 1987 and 2011, the 1987 papers included deeply recursive nominal groups such as:

[the graph [of the curve $\left[y=5+3 x-x^{2}\right.$ [for $\left.\left.\left.\left.-2 \leq x \leq 5\right]\right]\right]\right]$

[the volume [of material [required [to construct a pipe [of length [one metre ]] [having

this cross-section]]]]]

The most complex nominal groups found in the 2011 papers might be characterised as 'everyday' objects:

[information [about the points [scored [by some students] [in a spelling competition]]]]

while the specialised mathematical objects in this year had a maximum recursive depth of 3 :

[the expression [which is a factor [of $\left.\left.\left.4 n^{2}-1\right]\right]\right]$

[points [on the circumference [of a circle]]]

Halliday (1998) argues that the packing of information into complex nominal groups in scientific text is not arbitrary. Rather it functions to transform experience into knowledge, enabling the formation of precisely defined objects, which can act as participants in further processes. Figure 1 illustrates schematically how such information-packed objects may be inserted into an otherwise structurally simple instruction to "compare $\mathrm{X}$ with $\mathrm{Y}$ ".
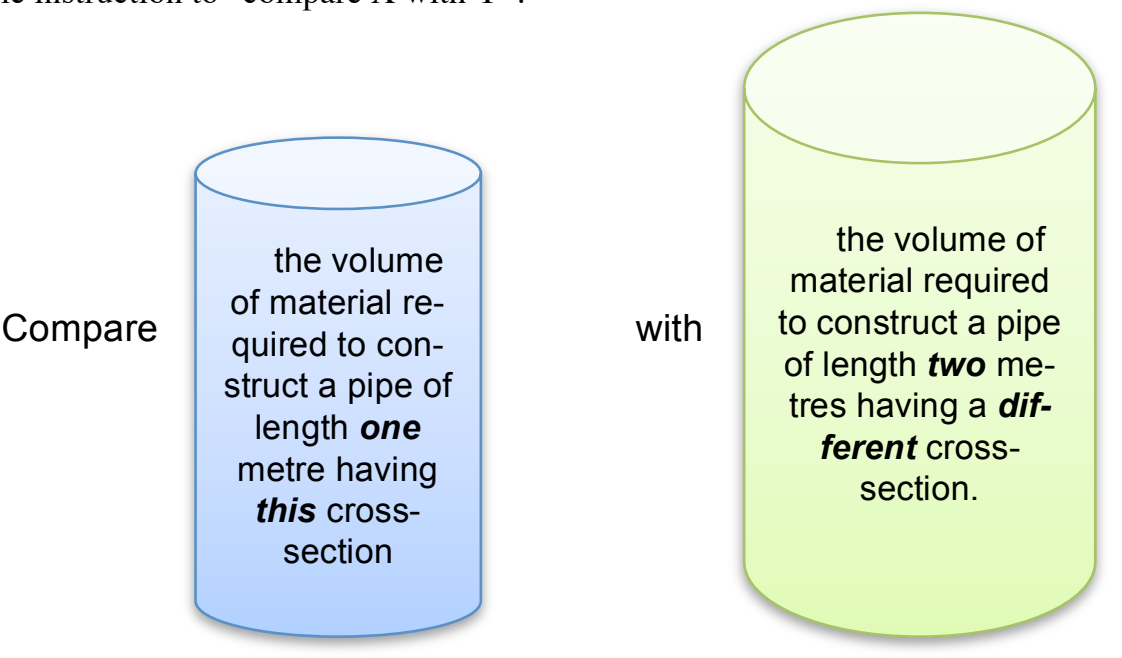

Fig. 1: Complex objects participating in a new process

${ }^{8}$ Recursive depth is defined as the maximum number of decompositions that can be performed. Decomposition is possible when a unit of language (clause, phrase, or word) contains a unit of the same or higher rank. In the given examples, square brackets are used to enclose such "rank-shifted" units. 
In our paper, we concluded:

The dense nominal groups in the 1987 papers incorporate the results of several mathematical processes as qualities of a single object. A consequence of this is that the (apparently simple) instruction to "calculate" in fact demands analysis of the structure of the object to be calculated and consideration of the form of the answer. In 2011 it seems that the processes of analysis, approximation and consideration of units are separated from calculation and that mathematical objects, being generally less complex, contain less potential for further mathematical activity.

When presenting this paper at a mathematics education conference, we were faced by two opposing types of responses from those attending our session. The first (minority) response was to value the simplification of the syntax as it was assumed to make questions more readable and hence to make the mathematical task more accessible to students. This type of response is consistent with the principles applied by the examination boards, which have been concerned to avoid linguistic difficulties 'obscuring' the mathematics. The second type of response (which on reflection was privileged by our own presentation) valued 'the mathematics', regretting the loss of complexity as a sign of loss of demand for 'higher' forms of mathematical activity or, in Dowling's terms, positioning students as dependent, denying them access to some of the principles of mathematical activity. Fellow researchers thus interpreted our description of syntactical features of examination questions in ways that were strongly coloured by their value systems. Participants in debate during the conference session drew on opposing positions within a discourse of access: either valuing access to opportunities to gain the material benefits of examination success or valuing access to the alternative intellectual benefits of specialised forms of participation in mathematics.

\section{Case 2 - Application of mathematics in context}

Another discursive characteristic that we investigated in EDSM was the degree of mathematical specialisation in the discourse. This was investigated at the level of vocabulary but also at the level of whole questions, considering whether questions were located only within a specialised mathematical discourse or whether they also drew on everyday or other discourses in order to relate to nonmathematical contexts.

The utility of mathematics in the real world is a strong element of current curriculum discourse in England, offered as a justification for the privileged place of mathematics in the school curriculum. A rise in the presence of contextualised questions in examinations can be traced to the late 1980s, following the Cockcroft report (DES, 1982) and paralleling the introduction of the first version of the $\mathrm{Na}$ tional Curriculum for England and Wales with its inclusion of "Using and Applying Mathematics" as a distinct attainment target (DES/WO, 1988). Since then, the presence of contextualised questions has fluctuated in response to various policy debates and curriculum changes. For example, concern expressed about levels of 
algebraic skills among more advanced students (Royal Society/JMC Working Group, 1997) and a report by the Qualification and Curriculum Authority noting the use of "trivial and distracting" contexts (QCA, 2006) can be associated with the increase in questions involving entirely specialised discourse from the late 1990s. The most recent development of so-called "functional mathematics" was not represented in our data set but is likely to be reflected in an increase of some kinds of contextualisation.

The chart in Figure 2 shows the variation in the proportion of examination questions involving only specialised mathematical discourse across the years in our sample. It also shows the proportions of contextualised questions necessitating different degrees of engagement with the context itself, from "ritual" questions in which the relationship between context and mathematics is formulaic, with similar questions found extensively in textbooks and other classroom materials (e.g., questions involving the probability of drawing balls or sweets out of a bag or calculating the original price of an item on sale with a discount of 10\%), through "mundane" questions, which, while less familiar than the ritual questions, allow straightforward identification of the mathematical facts and procedures required to solve them, to "deep" questions in which students would need to analyse or draw on additional knowledge of the context in order to determine what mathematical techniques they should use. ${ }^{9}$

While the proportion of entirely specialised questions has returned nearly to pre-Cockcroft levels (although their distribution across the various areas of the curriculum has changed), the proportion of questions demanding any significant engagement with the context has remained small throughout and the level of engagement demanded in the most recent years in our sample is very low, with less than $25 \%$ of questions in 2010 and 2011 involving anything more than ritual contextualisation.

\footnotetext{
${ }^{9}$ The distinction between ritual, mundane and deep contextualization is adapted from Nabayanga (2002)
} 


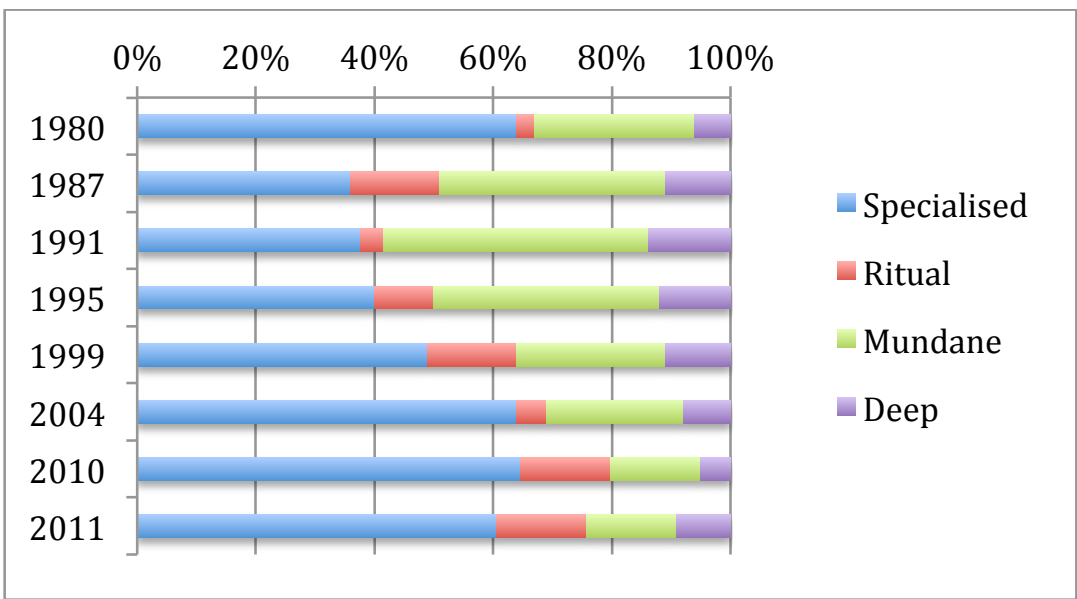

Fig. 2: Proportion of questions involving specialised mathematical discourse and different degrees of contextualisation

At the beginning of this section, I set the scene for considering contextualisation by reference to utility and the value that is placed on application of mathematics in official curriculum discourse in England. Framing a response to our analysis within this official discourse would be likely to identify a failure of the examinations to support the curricular aim. However, there are alternative discourses that affect the ways in which groups with different interests, including critical sociopolitical perspectives, will respond. A variety of such responses may be found within the field of mathematics education, for example:

- Mathematics educators arguing from a critical or social activist perspective (e.g., Gutstein, 2006; Skovsmose, 1994) might also point to a lack of genuine opportunities to use mathematics to understand, critique or act in the social world (though their critique of the examinations might start from a different place).

- Others, drawing on the research of Cooper and Dunne (2000), might note that students from different social groups are likely to be differentially advantaged by questions demanding some level of engagement with context. Cooper and Dunne's conclusion that working class students are more likely to draw on aspects of their knowledge of the context that are not implicated in the expected mathematical solution might lead to the suggestion that questions providing less contextual information and demanding less engagement with the context may be more equitable.

- Discourses drawing on Piagetian theory of learning might see contextualisation as a means of relating abstract mathematics to concrete ideas and hence supporting students to make sense of the abstract. In this case, the depth of the contextualisation may not be considered so 
significant. The aim of contextualisation is to enable operation with the specialised discourse, not to engage with the real world context.

- As deeper engagement with context generally involves more extensive description of that context and hence more use of language, criticism from the point of view that "the language obscures the mathematics" applies more strongly. Less or simpler language entails less, simpler context. Hence questions involving less significant engagement with context allow more students to access the necessary mathematics to be successful in the examination.

The EDSM analytic framework has allowed us to produce a description of the way contextualisation of examination questions has varied over the time period studied. The description will, however, lead to different evaluations of the observed change, depending on the interests of the respondents and the discourses they draw upon.

\section{So what is the problem?}

However much we, as researchers, may seek to present the outcomes of our research as pure description it is clear that each audience or "user" of our research, whether from within the research community, or practitioners, or policy makers, will interpret it by drawing on other resources arising from their interpretations of other research, from policy discourse, from public media, from the discourses current in school practices. Their recontextualisation of our research will select from our reports, relate these selections to their own interests and to selections from other sources, and, most significantly, attach positive or negative values to each selection according to principles and sets of values that are located within the users' own practices. In particular, government agencies will select those aspects of the research that can be made to support the messages they wish to promote.

Of course, the premise that the outcomes of our research could or should be value-free description is open to challenge. I have argued elsewhere (Morgan, 2014) that the theoretical positions that underpin all our research decisions are related to our understanding of society and our political orientation. Moreover, many researchers, especially those with stronger awareness of socio-political aspects of education, adopt explicit sets of values and political positions, using these to shape their choices of research focus, methodologies, relationships to research participants, and the ways in which they communicate and disseminate their research. Nevertheless, however explicit we may be about the principles by which our research outcomes are generated, once they are in the public domain they are subject to processes of recontextualisation.

While we have no control over the principles and values employed by the users of our research, we can anticipate what some of these may be. As shown earlier in this paper, from the beginning of our project we were aware of a dominant dis- 
course of falling standards, current in policy and in public media. At the same time, we were aware of a discourse of access, also employed within policy discourse. Interestingly, the examination boards attempt to engage simultaneously with the values of both these discourses, manipulating questions in order to allow more students to give correct answers to at least some parts of the examination, while setting cut-off scores for grades in order to manipulate the proportions of students awarded each grade, thus ensuring the appearance of maintaining standards.

In an attempt to position ourselves outside these discourses, we identified the policy standards discourse as focusing primarily on numbers - the scores achieved by students and the numbers of students achieving high grades - and distanced ourselves from this focus on numbers by focusing instead on the nature of the mathematics demanded of students. We deliberately avoided using the expression 'the quality of the mathematics' - but of course the various audiences of our research each attaches their own values to particular kinds of mathematics, whether prioritising fluent and accurate reproduction of standard procedures, reasoning in ways associated with more specialised academic mathematics practices, or the use of mathematics to solve real non-mathematical problems or to engage critically with the social world.

Our project did not address the issue of access directly. The discourse of access tends to rest on assumptions that "Mathematics for All" is an unquestionable principle and that assessment regimes should enable all students to demonstrate and gain credit for what they know and can do rather than be penalised for what they cannot do - an assessment principle enshrined in UK official policy rhetoric since the Cockcroft report (DES, 1982). The question of whether "Mathematics for All" is a meaningful or desirable goal is dealt with elsewhere (see e.g. Pais in this volume, and Gellert in this volume). By focusing on an existing assessment regime, my concern in relation to access is not so much with the extent of students' opportunities to learn mathematics (although the nature of the mathematics they experience is a focus) as with the consequences of the assessment regime on students' current and future experiences and opportunities. The high-stakes of the GCSE regime for individual students, for teachers and for schools mean that the nature of the mathematics included in the examinations has a strong influence on what happens in mathematics classrooms. The extent of this influence is likely to vary between schools and classrooms in a way that is at least partially linked to the social background of the pupils. Private schools in England that serve the children of the elite may even opt out of the GCSE examination at age 16 completely, focusing instead on strategies for maintaining their disproportionate success in accessing the elite universities, including providing support for the challenging mathematics examinations required for entrance to such universities to an extent that is not widely available to students in state schools. While all state funded schools are more closely regulated, it is those that are officially deemed to be "inadequate" - 
overwhelming serving working class communities ${ }^{10}$ - that are most likely to need to prioritise examination success at age 16 in order to preserve the continuing existence of the school and the reputation and jobs of the school management. I would argue therefore that our analysis of the nature of the mathematics of examination questions is likely to have its strongest influence on the classroom experience of working class children.

As examination success is strongly linked to future opportunities for further study and employment, it is necessary to consider the question of which groups of students may be advantaged or disadvantaged by particular ways of presenting examination questions. In particular, in considering how policy makers and practitioners may interpret and make use of our reports of the research, we must ask how resulting changes in policy and practice may affect students and teachers. Although we have attempted in a later phase of the project to identify how various characteristics of questions affect the ways students respond, the EDSM project did not attempt to look at whether or how such effects varied across groups of students. Nevertheless, we know from Cooper and Dunne's (2000) work that contextualisation of questions may disadvantage girls and students from working class backgrounds. It also seems likely that the use of complex syntax may disadvantage those with less fluency in the language of instruction or less access to academic forms of language. If policy makers interpret our research as evidence that the 'quality' of the mathematics demanded needs to be raised, for example by increasing the grammatical complexity, this may lead to changes that exacerbate existing disadvantage. If our research is taken as evidence of falling standards, we will have contributed to a discourse that is used to regulate schools, teachers and students; and to devalue the achievements of all but an elite few.

Of course, the overall logic of my argument implies that educational research is always recontextualised as it is appropriated into the domains of policy and practice and that policy makers will always make use of research in ways that reflect their existing interests. Though this is a general conclusion, its consequences seem especially immediate and severe in the context of research related to qualifications and standards because of the effects of examination success and failure on the futures of students and teachers. In conceiving the EDSM project, we were clearly naïve in attempting to distance ourselves from the dominant standards discourse and presenting our research as being only about mathematics. Or possibly we were disingenuous, acting out an illusory replacement activity as argued by Lundin and Christensen (in this volume). Does this mean that our research project was in itself misconceived, inevitably resulting in outcomes that may be recruited to support

10 The annual report for $2010-2011$ by the government's school inspection agency Ofsted stated "this year the fifth of schools serving the most deprived pupils were four times more likely to be found inadequate than the fifth of schools serving the least deprived pupils. Seventy-one per cent of schools serving the least deprived pupils were judged to be good or outstanding this year compared with $48 \%$ of schools serving the most deprived." (Ofsted, 2011) 
the dominant discourse and contribute to the maintenance of disadvantage? I argued earlier that our employers and the state either recontextualise our research to serve their own interests or dismiss and devalue it. However, there are other possible audiences for the products of our labour. As intellectual labourers we do not immediately give up all claims to our product in order that it shall be sold for the profit of our employer, but we may continue to use it for our own purposes as well. This allows an alternative, more optimistic conclusion. While recognising the likely fate of our research in the field of policy, we have the opportunity to offer our research outcomes to other groups - teachers, students, grass-roots community organisations, and opposition political activists - to use in ways that are shaped by the interests of these groups. This may involve stepping out of the role of researcher in order to engage in the social practices we seek to affect, being or becoming teachers, teacher educators, community members and political activists ourselves. In doing so, we can be agents in the recontextualisation of our research into a new field, relocating, selecting and transforming the "pure knowledge" of research into social action. We may attempt to shape the ways others interpret our research but must be realistic about the extent to which this is likely to be successful - and wary of the dangers of interpretations and consequent actions that may support policies and practices that we ourselves find inequitable or unethical.

\section{References}

Bernstein, B. (2000). Pedagogy, symbolic control and identity: Theory, research and critique (revised ed.). Lanham: Rowman and Littlefield.

Cooper, B., \& Dunne, M. (2000). Assessing children's mathematical knowledge: Social class, sex and problem-solving. Buckingham: Open University Press.

DES. (1982). Mathematics Counts: Report of the committee of inquiry into the teaching of mathematics in schools under the chairmanship of $\mathrm{Dr} W$. H. Cockcroft. London: HMSO.

DES/WO. (1988). Mathematics in the National Curriculum. London: HMSO.

Dowling, P. (1998). The sociology of mathematics education: Mathematical myths/ pedagogic texts. London: Falmer.

Dowling, P. (2009). Sociology as method: Departures from the forensics of culture, text and knowledge. Rotterdam: Sense Publishers.

Draper, H. (1978). Karl Marx's theory of revolution, Volume II: The politics of social classes. New York: Monthly Review Press.

Fisher-Hoch, H., Hughes, S., \& Bramley, T. (1997). What makes GCSE examination questions difficult? Outcomes of manipulating difficulty of GCSE questions. Paper presented at the British Educational Research Association Annual Conference, York. http://www.cambridgeassessment.org.uk/Images/109646-what-makes-gcse-examinationquestions-difficult-outcomes-of-manipulating-difficulty-of-gcse-questions.pdf. Accessed 15 January 2016

Gutstein, E. (2006). Reading and writing the world with mathematics: Towards a pedagogy for social justice. New York, NY: Routledge.

Haggarty, L., \& Pepin, B. (2002). An investigation of mathematics textbooks and their use in English, French and German classrooms: Who gets an opportunity to learn what? British Educational Research Journal, 28(4), 567-590. 
Halliday, M. A. K. (1978). Language as social semiotic: The social interpretation of language and meaning. London: Edward Arnold.

Halliday, M. A. K. (1993). Some grammatical problems in scientific English. In M. A. K. Halliday \& J. R. Martin (Eds.), Writing science: Literacy and discursive power (pp. 69-85). London: Falmer

Halliday, M. A. K. (1998). Things and relations: Regrammaticising experience as technical knowledge. In J. R. Martin \& R. Veel (Eds.), Reading science: Critical and functional perspectives on discourse of science (pp. 186-235). London: Routledge.

Lerman, S., \& Tsatsaroni, A. (1998). Why children fail and what the field of mathematics education can do about it: The role of sociology. In P. Gates (Ed.), Proceedings of the First International Mathematics Education and Society Conference (pp. 26-33). Nottingham: Centre for the Study of Mathematics Education, Nottingham University.

Morgan, C. (2014). Understanding practices in mathematics education: structure and text. Educational Studies in Mathematics, 87(2), 129-143. doi: 10.1007/s10649-013-9482-6

Morgan, C., \& Sfard, A. (forthcoming). Studying changes over time: an introduction to the project "The Evolution of the Discourse of School Mathematics".

Morgan, C., Tang, S., \& Sfard, A. (2011). Grammatical structure and mathematical activity: comparing examination questions. Proceedings of the British Society for Research into the Learning of Mathematics, 31(3). http://www.bsrlm.org.uk/IPs/ip31-3/BSRLM-IP-31-320.pdf. Accessed 15 January 2016

Morgan, C., Tsatsaroni, A., \& Lerman, S. (2002). Mathematics teachers' positions and practices in discourses of assessment. British Journal of Sociology of Education, 23(3), 445-461.

Nyabanyaba, T. (2002). Examining examination: The ordinary level (O level) mathematics examination in Lesotho and the impact of recent trends on Basotho students' epistemological access. Unpublished PhD thesis, University of the Witwatersrand, Johannesburg, South Africa.

Ofsted. (2011). The Annual Report of Her Majesty's Chief Inspector of Education, Children's Services and Skills 2010/11. London: HMSO.

https://www.gov.uk/government/publications/hm-chief-inspector-of-education-childrensservices-and-skills-annual-report-2010-to-2011. Accessed 15 January 2016.

Pais, A., \& Valero, P. (2014). Whither social theory? Educational Studies in Mathematics, 87(2), 241-248. doi: 10.1007/s10649-014-9573-z

Pollitt, A., Hughes, S., Ahmed, A., Fisher-Hoch, H., \& Bramley, T. (1998). The effects of structure on the demands in GCSE and A level questions. Cambridge: OCR.

QCA. (2006). Review of standards in mathematics: GCSE 1999-2004 and A level 1998-2004. London: Qualifications and Curriculum Authority.

Royal Society/JMC Working Group. (1997). Teaching and learning algebra pre-19. London: Royal Society/ Joint Mathematical Council.

Sfard, A. (2008). Thinking as communicating: Human development, the growth of discourses, and mathematizing. Cambridge: Cambridge University Press.

Sfard, A. (2009). Disabling numbers: on the secret charm of numberese and why it should be resisted. In L. Black, H. Mendick, \& Y. Solomon (Eds.), Mathematics relationships in education: Identities and participation (pp. 9-18). New York: Routledge.

Shorrocks-Taylor, D., \& Hargreaves, M. (1999). Making it clear: a review of language issues in testing with special reference to the National Curriculum mathematics tests at Key Stage 2. Educational Research, 41(2), 123-136. doi: 10.1080/0013188990410201

Skovsmose, O. (1994). Towards a philosophy of critical mathematics education. Dordrecht: Kluwer Academic Publishers.

Slavin, R. E. (2002). Evidence-based education policies: Transforming educational practice and research. Educational Researcher, 31(7), 15-21. doi: 10.3102/0013189x031007015 